\title{
Adição de molibdênio ao inoculante turfoso com bactérias diazotróficas usado em duas cultivares de arroz irrigado
}

\author{
Salomão Lima Guimarães ${ }^{(1)}$, José Ivo Baldani(2), Vera Lúcia Divan Baldani(2) e Jorge Jacob-Neto ${ }^{(1)}$
}

\begin{abstract}
(1) Universidade Federal Rural do Rio de Janeiro, Dep. de Fitotecnia, BR 465, Km 7, CEP 23890000 Seropédica, RJ. E-mail: slguimaraes@hotmail.com,jacob@ufrrj.br(2)Embrapa Agrobiologia, BR 465, Km 7, Caixa Postal 74505, CEP 23890000 Seropédica, RJ. E-mail: ibaldani@cnpab.embrapa.br, vera@cnpab.embrapa.br
\end{abstract}

Resumo - O objetivo deste trabalho foi avaliar o efeito da utilização de bactérias diazotróficas com ou sem molibdênio em duas cultivares de arroz com diferentes potenciais de fixação biológica de nitrogênio. Dois experimentos foram montados: o primeiro foi conduzido em condições gnotobióticas, com utilização das estirpes BR 11417 (ZAE94 - Herbaspirillum seropedicae) e BR 11340 (M130 - Burkholderia sp.), duas doses de molibdênio, 1,12 e 2,25 g, e duas fontes, molibdato de sódio e molibdato de amônio. As sementes foram peletizadas com inoculante turfoso com bactérias diazotróficas e o molibdênio. Em seguida as cultivares foram plantadas em tubos de ensaio com capacidade para $120 \mathrm{~mL}$ com $60 \mathrm{~mL}$ da solução de Hoagland sem nitrogênio por 30 dias. Foi avaliada a matéria seca das plantas. O segundo experimento foi conduzido em vasos em casa de vegetação, com as mesmas estirpes e dosagens de molibdênio. Foram avaliados a produção e o $\mathrm{N}$ total dos grãos. O delineamento estatístico foi inteiramente casualizado com quatro repetições e quatro plantas por vaso. Foram observados aumentos na produção de grãos nas cultivares IR42 e IAC4440 de 88 e 57\%, respectivamente, com a adição ao inoculante turfoso, das estirpes ZAE94 e M130 com molibdênio.

Termos para indexação: Oriza sativa, Herbaspirillum seropedicae, Burkholderia, molibdato de sódio, molibdato de amônio.

\section{Addition of molybdenum in peat innoculum with diazotrophic bacteria used in two rice cultivars}

\begin{abstract}
The objective of this work was to evaluate the effect of the inoculation of diazotrophic bacteria associated with the molybdenum in two rice cultivars. Two experiments were performed: the first one was lead under gnotobiotics conditions, using Herbaspirillum seropedicae, strain BR 11417 and Burkholderia sp., strain BR 11340, two doses of molybdenum (1.12 and $2.25 \mathrm{~g}$ ) and two different sources of Mo - sodium molybdate and ammonium molybdate. The seeds were pelleted with peat containing diazotrophic bacteria and molybdenum. After inoculations were seeds planted in to test tubes with capacity for $120 \mathrm{~mL}$ content $60 \mathrm{~mL}$ Hoagland solution without nitrogen. Seedlings were harvested after 30 days and plant dry weight was evaluated. The second experiment was held in greenhouse with the same strains, sources and amount of molybdenum. The production and the total $\mathrm{N}$ of the rice grains were evaluated. Statistical design was completely randomized with four replication and four plants per pot were planted. Grain production increased with the inoculation in the cultivars IR42 and IAC4440 up to 88 and $57 \%$, respectively.
\end{abstract}

Index terms: Oryza sativa, Herbaspirillum seropedicae, Burkholderia, sodium molybdate, ammonium molybdate.

\section{Introdução}

$\mathrm{O}$ arroz é uma cultura largamente difundida, com participação destacada na alimentação da população brasileira. Seu cultivo se dá em todos os estados brasileiros, podendo constituir-se, em alguns deles, a principal fonte de renda agrícola (Yokoyama et al., 1999).

O Brasil é o nono produtor mundial de arroz, com 10,6 milhões de toneladas de grãos por hectare. É uma cultura versátil, que se adapta a diferentes condições de clima, e é considerado a espécie com maior potencial de produção para o combate à fome no mundo, fornecendo $20 \%$ da energia e $15 \%$ da proteína per capita necessárias ao homem (Azambuja et al., 2004).

Há um aumento da demanda por alimentos no mundo e uma crescente competição pelo uso das terras agricultáveis e, por isso, o aumento da produtividade das culturas e a melhoria da eficiência de produção, com preservação dos recursos naturais, são aspectos importantes na agricultura moderna. 
A cultura do arroz é altamente dependente de fertilizantes, principalmente os nitrogenados, que aumentam a poluição do ambiente, contaminam os mananciais com nitrato, acidificam o solo e emitem gases como $\mathrm{N}_{2} \mathrm{O}$. A cultura do arroz, porém, apresenta eficiência baixa no uso desses fertilizantes (Reddy \& Ladha, 1995; Stoltzfus et al., 1997).

Uma das soluções para diminuir as aplicações de fertilizantes nitrogenados nos cultivos de arroz é a utilização da interação entre a planta e a bactéria diazotrófica, pois o maior potencial de fixação de nitrogênio do ar é atribuído às bactérias diazotróficas de caráter microaerofílico, como, por exemplo, as espécies dos gêneros Azospirillum, Herbaspirillum (Döbereiner, 1992), Gluconacetobacter (Yamada et al., 1997), Burkholderia (Baldani, 1996) e Azoarcus (ReinholdHurek et al., 1993), que colonizam partes internas das raízes e partes aéreas de gramíneas (Baldani et al., 1997). Não são conhecidos trabalhos sobre inoculante turfoso com molibdênio e sua utilização em plantas de arroz.

Na realização do processo de fixação biológica de nitrogênio, o molibdênio é um micronutriente essencial, cujas funções, na planta, estão relacionadas com o sistema de transferência de elétrons para a redução do nitrato e na fixação biológica de nitrogênio, que é feita pelas molibdoenzimas redutase do nitrato e nitrogenase, respectivamente (Gupta \& Lipsett, 1981).

O objetivo deste trabalho foi avaliar o efeito da utilização de bactérias diazotróficas com ou sem molibdênio, em duas cultivares de arroz, com diferentes potenciais de fixação biológica de nitrogênio (FBN).

\section{Material e Métodos}

Neste trabalho foram utilizadas cultivares de arroz contrastantes quanto ao potencial para a fixação biológica de nitrogênio (FBN), a IAC4440, que apresenta baixo potencial para FBN (Oliveira, 1994) e a IR42, com alto potencial para a fixação biológica de nitrogênio (Oliveira, 1994; Kundu \& Ladha, 1995; Wu et al., 1995).

No preparo do inoculante, o veículo utilizado foi a turfa, que teve o $\mathrm{pH}$ corrigido para 7 com carbonato de cálcio e foi esterilizada duas vezes em autoclave a $120^{\circ} \mathrm{C}$ durante 20 min, com intervalo de 24 horas entre cada esterilização (Straliotto, 2000).

As estirpes utilizadas foram BR 11417 - ZAE94 (Herbaspirillum seropedicae) e BR 11340 - M130 (Burkholderia sp.), multiplicadas em meio DYGS por um período de 24 horas. O inoculante foi preparado em sacos de polipropileno com $35 \mathrm{~g}$ de turfa. Em cada saco, foram adicionados $15 \mathrm{~mL}$ do caldo bacteriano contendo $10^{8}$ células por $\mathrm{mL}$ de cada estirpe e adicionadas duas doses de molibdênio: 1,12 e 2,25 g, adaptadas de Campo \& Lantmann (1997), sob as formas de molibdato de amônio e molibdato de sódio. Este inoculante turfoso foi colocado para incubar a $30^{\circ} \mathrm{C}$ por 24 horas.

As sementes das duas cultivares de arroz foram imersas numa solução contendo goma-arábica a $3 \%$ como adesivo. Em seguida, foram peletizadas com o inoculante e colocadas para secar à sombra. A proporção utilizada foi de $250 \mathrm{~g}$ de inoculante para cada $20 \mathrm{~kg}$ de sementes de arroz (Ferreira, 2004). Após a secagem, as sementes foram utilizadas para o plantio no experimento em casa de vegetação.

A fim de avaliar o efeito da adição de molibdênio ao inoculante turfoso, no acúmulo da matéria seca de plantas de arroz em condições gnotobióticas, foram utilizados tubos de ensaio com capacidade para $120 \mathrm{~mL}$, com $60 \mathrm{~mL}$ de solução de Hoagland ágar $\left(6 \mathrm{~g} \mathrm{~L}^{-1}\right) \mathrm{e}$ sem nitrogênio. Foram utilizadas duas fontes de molibdênio: molibdato de sódio e amônio. O delineamento experimental foi inteiramente casualizado, com duas cultivares de arroz, IR42 e IAC4440; duas bactérias diazotróficas, ZAE94 e M130; três níveis de molibdênio, $0,1,12$ e $2,25 \mathrm{~g}$, e quatro repetições.

O molibdênio foi aplicado diretamente no inoculante. Logo depois, realizou-se peletização das sementes. A semeadura foi feita diretamente nos tubos de ensaio com a solução de Hoagland, e foi mantida apenas uma planta por tubo. A coleta foi realizada 30 dias após a germinação das sementes, e foi avaliada a matéria seca das plantas.

A fim de avaliar o efeito da adição de molibdênio ao inoculante turfoso, na produção de grãos, e o acúmulo de nitrogênio em plantas de arroz, cultivadas em casa de vegetação, a semeadura foi realizada em vasos com $8 \mathrm{~kg}$ de solo provenientes dos primeiros $20 \mathrm{~cm}$ de um Planossolo Série Ecologia, coletado no campo experimental da Embrapa Agrobiologia. De acordo com a análise de solo, cada vaso recebeu o equivalente a $20 \mathrm{~kg}$ de $\mathrm{P}_{2} \mathrm{O}_{5}$ e $50 \mathrm{~kg}$ de $\mathrm{K}_{2} \mathrm{O}$. A aplicação do nitrogênio foi realizada em solução, aos 30 dias após a germinação das sementes. Foram plantadas três sementes por vasos, e após a germinação, todas as plantas foram mantidas até a realização da coleta.

Em todos os tratamentos com as bactérias diazotróficas, as plantas originaram-se de sementes peletizadas. Foi utilizada uma testemunha nitrogenada, com dosagem equivalente a $100 \mathrm{~kg} \mathrm{ha}^{-1} \mathrm{de} \mathrm{N}$, na forma de sulfato de amônio. A coleta foi realizada no final do ciclo de cada cultivar. Os parâmetros avaliados foram a produção de grãos e o conteúdo de nitrogênio $(\mathrm{N}$ total) dos grãos. 
O delineamento utilizado foi o inteiramente casualizado, com duas cultivares de arroz, IR42 e IAC4440; três doses de molibdênio, 0, 1,12 e 2,25 g; duas bactérias, ZAE94 e M130, e quatro repetições. Como fontes de molibdênio, foram utilizados o molibdato de sódio e o molibdato de amônio, aplicados diretamente no inoculante.

\section{Resultados e Discussão}

No experimento em que foi avaliado o efeito da aplicação de diferentes fontes e doses de molibdênio em inoculante turfoso com bactérias diazotróficas, na massa seca de plantas de arroz, foram observados efeitos positivos da inoculação na cultivar IR42. Obtiveram-se melhores resultados quando foi adicionado molibdato de amônio ao inoculante turfoso com a estirpe ZAE94 de Herbaspirillum seropedicae, e molibdato de sódio ao inoculante com a estirpe M130 de Burkholderia sp., o que indica ocorrência de especificidade entre as diferentes espécies de bactérias diazotróficas utilizadas e as fontes e doses de molibdênio (Tabela 1).

A cultivar IR42 apresentou resposta positiva à inoculação nos tratamentos com a estirpe ZAE94 + 1,12 g de Mo na forma de molibdato de amônio e a estirpe $\mathrm{M} 130+2,25 \mathrm{~g}$ de Mo na forma de molibdato de sódio, que proporcionou aumento de até $23 \%$ na matéria seca das plantas em comparação com a testemunha sem bactéria e sem molibdênio (Tabela 1).

Grande parte dos trabalhos que utilizam molibdênio é realizada com plantas leguminosas, principalmente a soja. O molibdênio é requerido pelas plantas em quantidades

Tabela 1. Efeito da adição de molibdênio ao inoculante turfoso com bactérias diazotróficas, sobre a massa de matéria seca de plantas de arroz, cultivar IR42 em condições gnotobióticas ${ }^{(1)}$.

\begin{tabular}{lll}
\hline Espécie & Tratamentos & $\begin{array}{c}\text { Matéria seca } \\
\left(\mathrm{g} \mathrm{planta}^{-1}\right)\end{array}$ \\
\hline ZAE94 & Sem molibdênio & $0,0800 \mathrm{def}$ \\
& $1,12 \mathrm{~g}$ molibdato de amônio & $0,1033 \mathrm{a}$ \\
& 2,25 g molibdato de amônio & $0,0586 \mathrm{~g}$ \\
& $1,12 \mathrm{~g}$ molibdato de sódio & $0,0786 \mathrm{def}$ \\
& 2,25 g molibdato de sódio & $0,0890 \mathrm{bcd}$ \\
\hline M130 & Sem molibdênio & $0,0860 \mathrm{cde}$ \\
& 1,12 g molibdato de amônio & $0,0683 \mathrm{fg}$ \\
& 2,25 g molibdato de amônio & $0,0833 \mathrm{cde}$ \\
& 1,12 g molibdato de sódio & $0,0880 \mathrm{bcd}$ \\
\hline Testemunha & 2,25 g molibdato de sódio & $0,1006 \mathrm{ab}$ \\
\hline CV (\%) & & $0,0840 \mathrm{cde}$ \\
\hline
\end{tabular}

(1)Valores seguidos da mesma letra não diferem entre si pelo teste de Tukey, a 5\% de probabilidade; ZAE94, Herbaspirillum seropedicae; M130, Burkholderia sp. muito pequenas. Mesmo assim, Jacob-Neto \& Franco (1986) expuseram a importância da determinação do nível crítico do molibdênio nas sementes e nas plantas. Esses autores concluíram que apenas 3,51 $\mu \mathrm{g}$ de Mo por semente, em algumas cultivares de feijão, é suficiente para que as plantas possam se desenvolver sem a necessidade de adubação complementar à base de molibdênio.

De acordo com Das Gupta \& Basuchaudhuri (1977), a aplicação de molibdênio por via foliar, com adição de nitrogênio mineral, apresenta efeito positivo no acúmulo de massa seca na cultivar de arroz IR8. Estes efeitos também foram observados nas culturas de feijão e soja, porém sem a aplicação de nitrogênio (Jacob-Neto et al., 1988).

Fageria \& Baligar (1997), em experimentos com arroz, a fim de verificar deficiências nutricionais, observaram que as plantas apresentaram redução na massa seca nos tratamentos sem molibdênio. Entretanto, plantas nutridas com este micronutriente mostraram incrementos na massa seca em relação à testemunha.

A cultivar IAC4440 respondeu positivamente à estirpe ZAE94, mesmo sem adição de molibdênio. Por sua vez, a utilização da estirpe M130 com a adição de molibdato de sódio, resultou em acúmulo de massa seca inferior ao tratamento que continha a estirpe ZAE94 e superior à testemunha (Tabela 2).

As plantas com a estirpe ZAE94 + 1,12 g Mo, na forma de molibdato de amônio, apresentaram incrementos de $72 \%$ na massa seca, e a inoculação da estirpe $\mathrm{M} 130+2,25 \mathrm{~g}$ de Mo, na forma de molibdato de sódio, promoveu aumento de $62 \%$ quando comparado à testemunha (Tabela 2).

Em trabalhos sobre utilização de bactérias diazotróficas em arroz, conduzidos em condições gnotobióticas, há relatos de efeitos positivos no acúmulo de massa seca de plantas de arroz (Baldani et al., 2000; Guimarães et al., 2003; Sabino, 2003; Ferreira, 2004), com incrementos de até $124 \%$ na massa seca das plantas em relação à testemunha. Também foi observado que variações no ganho de massa de matéria seca entre as estirpes testadas indicam eficiência variável das estirpes na associação com plantas de arroz. Entretanto, efeitos da aplicação de molibdênio não têm sido relatados nessas condições experimentais.

Os veículos utilizados para inoculação também podem interferir no sucesso dos experimentos testados. Ferreira et al. (2003) observaram que o uso de veículo oleoso, por exemplo, prejudicou a germinação das sementes de arroz tanto sob condições gnotobióticas quanto em condições de campo, pois a formação de uma camada oleosa na superfície das sementes dificultou a absorção de água pelas sementes, impedindo a sua germinação. 
$\mathrm{Na}$ análise do efeito da adição de molibdênio ao inoculante turfoso na produção de grãos e acúmulo de nitrogênio, em plantas de arroz cultivadas em casa de vegetação, foi observado que, na cultivar IR42, a produção de grãos da maioria dos tratamentos foi superior à da testemunha (Tabela 3).

Os tratamentos ZAE94 com 2,25 g de molibdato de amônio, M130 com 1,12 e 2,25 g de molibdato de amônio, assim como M130 com 1,12 g de molibdato de sódio foram estatisticamente iguais ao tratamento em que as plantas receberam adubação nitrogenada na dosagem de $100 \mathrm{~kg} \mathrm{ha}^{-1}$ de $\mathrm{N}$ e foram superiores à testemunha absoluta. Neste caso, o aumento na produção de grãos foi de 64, 60, 82 e 57\%, respectivamente. Embora não tenham sido observadas diferenças entre a inoculação das estirpes ZAE94 e M130 e a testemunha, foram observados aumentos de 43 e $45 \%$ respectivamente, na produção de grãos (Tabela 3). Há relatos em alguns trabalhos de que a aplicação de molibdênio na cultura do arroz contribuiu com aumento na produção de grãos, confirmando a importância desse micronutriente para o desenvolvimento das plantas de arroz (Rafey et al., 1992; Muralidhararan \& Jose, 1994; Trivedi \& Verma, 1996).

Em relação ao acúmulo de nitrogênio nos grãos, também foram encontradas diferenças significativas. Os maiores valores foram alcançados nos grãos cujas plantas haviam recebido a inoculação das estirpes ZAE94 com 2,25 g de molibdato de amônio e M130 com 2,25 g de molibdato de amônio, correspondendo a 64 e $88 \%$, respectivamente, quando comparados à testemunha absoluta (Tabela 3).

Tabela 2. Efeito da adição de molibdênio ao inoculante turfoso com bactérias diazotróficas, sobre a massa de matéria seca de plantas de arroz, cultivar IAC4440 em condições gnotobióticas $^{(1)}$.

\begin{tabular}{llc}
\hline Espécie & Tratamentos & $\begin{array}{c}\text { Matéria seca } \\
\left(\mathrm{g} \mathrm{planta}^{-1}\right)\end{array}$ \\
\hline ZAE94 & Sem molibdênio & $0,1603 \mathrm{a}$ \\
& 1,12 g molibdato de amônio & $0,1573 \mathrm{ab}$ \\
& 2,25 g molibdato de amônio & $0,1320 \mathrm{c}$ \\
& 1,12 g molibdato de sódio & $0,0776 \mathrm{f}$ \\
2,25 g molibdato de sódio & $0,1266 \mathrm{c}$ \\
\hline M130 & Sem molibdênio & $0,0633 \mathrm{~g}$ \\
& 1,12 g molibdato de amônio & $0,1153 \mathrm{~d}$ \\
& 2,25 g molibdato de amônio & $0,1110 \mathrm{~d}$ \\
& 1,12 g molibdato de sódio & $0,1130 \mathrm{~d}$ \\
& 2,25 g molibdato de sódio & $0,1486 \mathrm{~b}$ \\
\hline Testemunha & & $0,0916 \mathrm{e}$ \\
\hline CV (\%) & & 4,45 \\
\hline
\end{tabular}

(1)Valores seguidos da mesma letra não diferem entre si pelo teste de Tukey, a 5\% de probabilidade; ZAE94, Herbaspirillum seropedicae; M130, Burkholderia sp.
A adubação com $100 \mathrm{~kg} \mathrm{ha}^{-1}$ de $\mathrm{N}$ promoveu os maiores ganhos de produção e acúmulo de nitrogênio nos grãos (103 e 129\%). No entanto, a inoculação de bactérias diazotróficas com a adição de molibdênio apresentou potencial para utilização.

Estes resultados corroboram os de Lantmann et al. (1989), que salientam a importância do molibdênio para o crescimento e o desenvolvimento dos vegetais, por ele ter participação importante no metabolismo do nitrogênio.

Mesmo sendo considerada como de baixo potencial para a fixação biológica de nitrogênio (Oliveira, 1994), a cultivar IAC4440 mostrou efeitos positivos da inoculação tanto na produção de grãos quanto no acúmulo de nitrogênio nos grãos.

As estirpes ZAE94 e M130, quando inoculadas isoladamente, não apresentaram diferenças em relação à testemunha sem inoculação, nitrogênio e molibdênio, mas apresentaram incrementos na produção de grãos de $30 \mathrm{e}$ $16 \%$, respectivamente (Tabela 4). As plantas dessa cultivar, com inoculação da estirpe ZAE94 e com 2,25 g de molibdato de sódio, tiveram a produção de grãos estatisticamente iguais às plantas que receberam $100 \mathrm{~kg} \mathrm{ha}^{-1}$ de $\mathrm{N}$.

Sundim et al. (2002) estudaram o efeito do molibdênio associado ao nitrogênio e a bactérias diazotróficas em diferentes cultivares de arroz, e observaram que a aplicação de Mo associado à inoculação da bactéria Herbaspirillum seropedicae (ZAE94) proporcionou aumentos de 33 a $37 \%$ na produção de grãos, dependendo da cultivar utilizada.

Maior acúmulo de nitrogênio nos grãos foi observado nos tratamentos que receberam a adição de molibdênio. No tratamento com a estirpe M130 com 2,25 g de molibdato de sódio, o acúmulo de nitrogênio nos grãos foi de $57 \%$ em relação à testemunha absoluta (Tabela 4). Semelhantemente à cultivar IR42, o maior aumento tanto na produção quanto no acúmulo de $\mathrm{N}$ nos grãos, ocorreu em plantas adubadas com $100 \mathrm{~kg} \mathrm{ha}^{-1}$ de N (98 e 89\%, respectivamente). Pôde ser observado o potencial de utilização de bactérias diazotróficas e molibdênio em inoculante turfoso, pois, em alguns tratamentos, mostraram-se estatisticamente iguais à adubação nitrogenada com $100 \mathrm{~kg} \mathrm{ha}^{-1}$ de $\mathrm{N}$.

Guimarães et al. (2003) estudaram o efeito da inoculação de bactérias diazotróficas em arroz cultivado sob condições de campo e observaram que houve respostas expressivas à inoculação com aumentos na produção de grãos de até $50 \%$, quando comparadas à testemunha sem inoculação. 
Tabela 3. Efeito da adição de molibdênio ao inoculante turfoso com bactérias diazotróficas sobre produção de grãos e nitrogênio total dos grãos de arroz, cultivar IR42, em condições de casa de vegetação. Médias de quatro repetições ${ }^{(1)}$.

\begin{tabular}{llcc}
\hline Espécie & Tratamentos & Produção de grãos $\left.(\mathrm{g} \mathrm{planta})^{-1}\right)$ & $\mathrm{N}$ total $\left(\mathrm{g} \mathrm{planta}^{-1}\right)$ \\
\hline ZAE94 & Sem molibdênio & $17,00 \mathrm{bcd}$ & $0,24 \mathrm{bcd}$ \\
& 1,12 g molibdato de amônio & $15,57 \mathrm{~cd}$ & $0,21 \mathrm{~cd}$ \\
& 2,25 g molibdato de amônio & $19,54 \mathrm{abc}$ & $0,28 \mathrm{bc}$ \\
& $1,12 \mathrm{~g}$ molibdato de sódio & $15,78 \mathrm{~cd}$ & $0,21 \mathrm{~cd}$ \\
& 2,25 g molibdato de sódio & $15,26 \mathrm{~cd}$ & $0,24 \mathrm{bcd}$ \\
\hline M130 & Sem molibdênio & $17,23 \mathrm{bcd}$ & $0,26 \mathrm{bcd}$ \\
& 1,12 g molibdato de amônio & $19,06 \mathrm{abc}$ & $0,27 \mathrm{bc}$ \\
& 2,25 g molibdato de amônio & $21,70 \mathrm{ab}$ & $0,32 \mathrm{ab}$ \\
& $1,12 \mathrm{~g}$ molibdato de sódio & $18,70 \mathrm{bc}$ & $0,23 \mathrm{~cd}$ \\
\hline $100 \mathrm{~kg} \mathrm{ha}^{-1}$ de N & 2,25 g molibdato de sódio & $17,67 \mathrm{bc}$ & $0,24 \mathrm{bcd}$ \\
Testemunha & & $24,17 \mathrm{a}$ & $0,39 \mathrm{a}$ \\
\hline
\end{tabular}

${ }^{(1)}$ Valores seguidos da mesma letra não diferem entre si pelo teste de Tukey, a 5\% de probabilidade; ZAE94, Herbaspirillum seropedicae; M130, Burkholderia sp.; o coeficiente de variação foi de $13,03 \%$.

Tabela 4. Efeito da adição de molibdênio ao inoculante turfoso com bactérias diazotróficas sobre a produção de grãos e nitrogênio total dos grãos de arroz, cultivar IAC4440, em condições de casa de vegetação. Médias de quatro repetições ${ }^{(1)}$.

\begin{tabular}{|c|c|c|c|}
\hline Espécie & Tratamentos & Produção de grãos (g planta $\left.{ }^{-1}\right)$ & $\mathrm{N}$ total $\left(\mathrm{g}_{\text {planta }}{ }^{-1}\right)$ \\
\hline \multirow[t]{5}{*}{ ZAE94 } & Sem molibdênio & $16,74 b c$ & $0,22 b$ \\
\hline & 1,12 g molibdato de amônio & $19,36 \mathrm{abc}$ & $0,25 b$ \\
\hline & 2,25 g molibdato de amônio & $18,58 \mathrm{abc}$ & $0,26 a b$ \\
\hline & $1,12 \mathrm{~g}$ molibdato de sódio & $15,25 \mathrm{bc}$ & $0,26 a b$ \\
\hline & $2,25 \mathrm{~g}$ molibdato de sódio & $20,19 \mathrm{ab}$ & $0,26 \mathrm{ab}$ \\
\hline \multirow[t]{5}{*}{ M130 } & Sem molibdênio & $14,94 \mathrm{bc}$ & $0,21 b$ \\
\hline & 1,12 g molibdato de amônio & $19,02 \mathrm{abc}$ & $0,22 b$ \\
\hline & 2,25 g molibdato de amônio & $18,61 \mathrm{abc}$ & $0,25 b$ \\
\hline & $1,12 \mathrm{~g}$ molibdato de sódio & $17,12 \mathrm{bc}$ & $0,23 b$ \\
\hline & 2,25 g molibdato de sódio & $18,35 \mathrm{bc}$ & $0,30 \mathrm{ab}$ \\
\hline $100 \mathrm{~kg} \mathrm{ha}^{-1}$ de N & & $25,51 \mathrm{a}$ & $0,36 \mathrm{a}$ \\
\hline Testemunha & & $12,85 \mathrm{c}$ & $0,19 \mathrm{~b}$ \\
\hline
\end{tabular}

${ }^{(1)}$ Valores seguidos da mesma letra não diferem entre si pelo teste de Tukey, a 5\% de probabilidade; ZAE94, Herbaspirillum seropedicae; M130, Burkholderia sp.; o coeficiente de variação foi de $13,00 \%$.

\section{Conclusões}

1. As estirpes BR 11417 (ZAE94) e BR 11340 (M130) com molibdênio promovem acúmulo de massa de matéria seca nas plantas de arroz das cultivares IR42 e IAC4440 em condições gnotobióticas.

2. As estirpes BR 11417 (ZAE94) e BR 11340 (M130) com molibdênio contribuem para o aumento na produção de grãos e para o acúmulo de nitrogênio dos grãos em condições de vasos em casa de vegetação.

\section{Agradecimentos}

À Embrapa Agrobiologia e à Universidade Federal Rural do Rio de Janeiro, pela oportunidade de realização do trabalho; à Capes, pela bolsa concedida ao primeiro autor; ao Pronex II/Finep, pelo apoio financeiro.

\section{Referências}

AZAMBUJA, I.H.V.; VERNETTI JUNIOR, F.J.; MAGALHÃES JUNIOR, A.M. Aspectos socioeconômicos da produção do arroz. In: GOMES, A. da S.; MAGALHÃES JÚNIOR, A.M. de (Ed.). Arroz irrigado no Sul do Brasil. Brasília: Embrapa Informação Tecnológica, 2004. p.23-44.

BALDANI, J.I.; CARUSO, L.; BALDANI, V.L.D.; GOI, S.R.; DÖBEREINER, J. Recent advances in BFN with non-legume plants. Soil Biology and Biochemistry, v.29, p.911-922, 1997.

BALDANI, V.L.D. Efeito da inoculação de Herbaspirillum spp. no processo de colonização e infecção de plantas de arroz e, ocorrência e caracterização parcial de uma nova bactéria diazotrófica. 1996. 290p. Tese (Doutorado) - Universidade Federal Rural do Rio de Janeiro, Seropédica.

BALDANI, V.L.D.; BALDANI, J.I.; DÖBEREINER, J. Inoculation of rice plants with the endophytic diazotrophs Herbaspirillum 
seropedicae and Burkholderia spp. Biology and Fertility of Soils, v.30, p.485-491, 2000.

CAMPO, R.J.; LANTMANN, A.F. Efeitos de micronutrientes na fixação biológica de nitrogênio e produtividade de soja. Pesquisa Agropecuária Brasileira, v.33, p.1245-1253, 1997.

DAS GUPTA, D.K.; BASUCHAUDHURI, P. Molybdenum nutrition of rice under low and high nitrogen level. Plant and Soil, v.46, p.681-685, 1977.

DÖBEREINER, J. History and new perspectives of diazotrophs in association with non-leguminous plants. Symbiosis, v.13, p.1-13, 1992.

FAGERIA, N.K.; BALIGAR, V.C. Response of common bean, upland rice, corn, wheat and soybean to soil fertility of an Oxisol. Journal of Plant Nutrition, v.20, p.1279-1289, 1997.

FERREIRA, J.S. Seleção e avaliação de veículos para inoculação de bactérias diazotróficas na cultura do arroz inundado. 2004. 44p. Dissertação (Mestrado) - Universidade Federal Rural do Rio de Janeiro, Seropédica.

FERREIRA, J.S.; SABINO, D.C.C.; GUIMARÃES, S.L.; BALDANI, J.I.; BALDANI, V.L.D. Seleção de veículos para o preparo de inoculante com bactérias diazotróficas para arroz inundado. Agronomia, v.37, p.6-12, 2003.

GUIMARÃES, S.L.; BALDANI, J.I.; BALDANI, V.L.D. Efeito da inoculação de bactérias diazotróficas endofíticas em arroz de sequeiro. Agronomia, v.37, p.25-30, 2003.

GUPTA, U.C.; LIPSETT, J. Molybdenum in soils, plants, and animals. Advances in Agronomy, v.34, p.73-115, 1981.

JACOB-NETO, J.; FRANCO, A.A. Adubação de molibdênio em feijoeiro. Seropédica: Embrapa-CNPAB, 1986. 4p. (EmbrapaCNPAB. Comunicado técnico, 1).

JACOB-NETO, J.; THOMAS, R.J.; FRANCO, A.A. Variação estacional da concentração de molibdênio nos nódulos e demais partes da planta de feijoeiro (Phaseolus vulgaris L.). Turrialba, v.38, p.51$58,1988$.

KUNDU, D.K.; LADHA, J.K. Enhancing soil-nitrogen use and biological nitrogen-fixation in wetland rice. Experimental Agriculture, v.31, p.261-277, 1995.

LANTMANN, A.F.; SFREDO, G.J.; BORKERT, C.M.; OLIVEIRA, M.C.N. de. Resposta da soja a molibdênio em diferentes níveis de pH do solo. Revista Brasileira de Ciência do Solo, v.13, p.45-49, 1989.

MURALIDHARAN, P.; JOSE, A.L. Effect of boron and molybdenum on the uptake of nutrients in rice. Journal of Tropical Agriculture, v.32, p.157-158, 1994.

OLIVEIRA, O.C. Quantificação da fixação biológica de nitrogênio em arroz (Oriza sativa L.) inundado. 1994. 135p. Dissertação (Mestrado) - Universidade Federal Rural do Rio de Janeiro, Seropédica.
RAFEY, A.; PANDE, H.K.; MITTRA, B.N. Effect of micronutrients and grain moisture content at harvest on yield and milling quality of rice. Journal of Research, Birsa Agricultural University, v.4, p.71-74, 1992.

REDDY, P.M.; LADHA, J.K. Can symbiotic nitrogen fixation be extended to rice? In: TIKHONOVICH, I.A.; PROVOROV, N.A.; ROMAVOV, V.I.; NEWTON, W.E. (Ed.). Nitrogen fixation: fundamentals and applications. Dordrecht: Kluwer Academic Publishers, 1995. p.629-634. (Current plant science and biotechnology in agriculture, 27).

REINHOLD-HUREK, B.; HUREK, T.; GILLIS, M.; HOSTE, B.; VANCANNEY, M.; KERSTERS, K.; LEY, J. de. Azoarcus gen. nov., nitrogen-fixing proteobacteria associated with roots of kallar grass (Leptochloa fusca (L.) Kunth) and description of two species, Azoarcus indigens sp. nov. and Azoarcus communis sp. nov. International Journal of Systematic Bacteriology, v.43, p.574$584,1993$.

SABINO, D.C.C. Metabolismo de nitrogênio em plantas de arroz (Oryza sativa L.) em associação com bactérias diazotróficas endofíticas. 2003. 75p. Dissertação (Mestrado) - Universidade Federal Rural do Rio de Janeiro, Seropédica.

STOLTZFUS, J.R.; SO, R.; MALARVITHI, P.P.; LADHA, J.K.; BRUIJN, F.J. Isolation of endophytic bacteria from rice and assessment of their potential for supplying rice with biologically fixed nitrogen. Plant and Soil, v.194, p.25-36, 1997.

STRALIOTTO, R. Protocolo operacional para o preparo da turfa para inoculante rizobiano. Seropédica: Embrapa Agrobiologia, 2000. 4p.

SUNDIM, M.F. do C.A.M.; ALVES, J.M.; BALDANI, V.L.D.; GOI, S.R.; JACOB-NETO, J. Respostas de cultivares de arroz à aplicação de molibdênio e diferentes fontes de nitrogênio. Agronomia, v.36, p.56-61, 2002.

TRIVEDI, J.K.; VERMA, M.M. Quality of rice (Oryza sativa L.) as affected by potassium sources with molybdenum. Journal of Soils and Crops, v.6, p.102-104, 1996.

WU, P.; ZHANG, G.; LADHA, J.K.; McCOUCH, S.R.; HUANG, N. Molecular-marker-facilitated investigation on the ability to stimulate $\mathrm{N}_{2}$ fixation in the rhizosphere by irrigated rice plants. Theoretical and Applied Genetics, v.91, p.1177-1183, 1995.

YAMADA, Y.; HOSHINO, K.; ISHIKAWA, T. Taxonomic studies of acetic acid bacteria and allied organisms. 11. The phylogeny of acetic acid bacteria based on the partial sequences of $16 \mathrm{~s}$ ribossomal RNA: the elevation of the subgenus Gluconoacetobacter to generic level. Bioscience Biotechnology and Biochemistry, v.61, p.12441251, 1997.

YOKOYAMA, L.P.; RUCATTI, E.G.; KLUTHCOUSKI, J. Economia da produção: conjuntura, mercados e custos. In: VIEIRA, N.R. de A.; SANTOS, A.B. dos; SANT'ANA, E.P. (Ed.). A cultura do arroz no Brasil. Santo Antônio de Goiás: Embrapa-CNPAF, 1999. p.36-57. 